\title{
Contaminação de enxertos de tendões flexores na reconstrução do ligamento cruzado anterior: comparação de duas técnicas de retirada*
}

\section{Hamstring Tendon Autograft Contamination in Anterior Cruciate Ligament Reconstruction: Comparison between two Harvesting Techniques}

\author{
Eduardo Frois Temponi ${ }^{10}$ Luís Henrique Grassi Marques da Costa ${ }^{1}$ Luiz Fernando Machado Soares ${ }^{1}$ \\ Lúcio Honório de Carvalho Júnior ${ }^{1,2,3}$
}

${ }^{1}$ Hospital Madre Teresa, Belo Horizonte, MG, Brasil

2 Faculdade de Medicina, Departamento do Aparelho Locomotor,

Universidade Federal de Minas Gerais, Belo Horizonte, MG, Brasil

${ }^{3}$ Departamento de Medicina, Pontifícia Universidade Católica, Belo

Address for correspondence Eduardo Frois Temponi, MD Hospital Madre Teresa, Belo Horizonte, MG, Brasil

Horizonte, MG, Brasil

Rev Bras Ortop 2019;54:45-52.

\section{Resumo \\ Palavras-chave \\ - enxerto de flexores \\ - reconstrução do ligamento cruzado anterior \\ - infecção \\ - artrite séptica \\ Objetivo: Avaliar a taxa de contaminação de autoenxerto de tendões flexores comparando duas técnicas e verificar se a contaminação intraoperatória está associada ao desenvolvimento de infecção clínica em pacientes submetidos a reconstrução do ligamento cruzado anterior. \\ Métodos: Foram feitas 110 reconstruções do ligamento cruzado anterior com tendão dos flexores e divididas em dois grupos: 1 ) técnica com retirada total dos tendões flexores e 2) técnica que manteve a inserção tibial desses tendões. Durante o preparo, dois fragmentos de cada um desses foram enviados para cultura, sendo mensurado o tempo de retirada dos tendões, do preparo dos tendões e total da cirurgia. Com 24 horas de pós-operatório, foi dosada a proteína $\mathrm{C}$ reativa. Seguimento clínico ambula- torial foi realizado de forma protocolada até 180 dias de pós-operatório. \\ Resultados: Apesar de terem sido observadas duas infecções pós-operatórias, não houve contaminação dos enxertos nem diferença entre os grupos em relação ao tempo de preparo dos enxertos e a proteína $C$ reativa com 24 horas de pós-operatório. A técnica clássica apresentou maior tempo de retirada do enxerto $(p=0,038)$ e não houve diferença estatística entre os dois grupos no que tange ao grau de contaminação e consequente infecção clínica, embora dois pacientes do grupo 2 tenham tido infecção com culturas perioperatórias negativas.}

Trabalho desenvolvido no Hospital Madre Teresa, Belo Horizonte, MG, Brasil. Publicado originalmente por Elsevier Editora Ltda. (C) 2018 Sociedade Brasileira de Ortopedia e Traumatologia.

(1) Eduardo Frois Temponi's ORCID is https://orcid.org/0000-00023002-9870.

received

July 1,2017

accepted

September 5, 2017

published online

January 6, 2018
DOI https://doi.org/

10.1016/j.rbo.2017.09.008. ISSN 0102-3616.
Copyright $\odot 2019$ by Sociedade Brasileira License terms de Ortopedia e Traumatologia. Published by Thieme Revnter Publicações Ltda, Rio de Janeiro, Brazil 


\begin{abstract}

\section{Keywords}

- flexor graft

- anterior cruciate ligament reconstruction

- infection

- septic arthritis

Objective: To evaluate the contamination rate of hamstring tendon autografts by comparing two different techniques, and to verify whether intraoperative contamination is associated with the development of clinical infection in patients submitted to reconstruction of the anterior cruciate ligament $(\mathrm{ACL})$.

Methods: A total of 110 hamstring tendon autograft $\mathrm{ACL}$ reconstructions were performed and divided into two groups: 1-hamstring tendon retraction technique; and 2 - technique maintaining the tibial insertion of the hamstring tendon. During the preparation, two graft fragments were sent for culturing; the harvesting time, the preparation time, and the total surgery time were measured. Twenty-four hours after the surgery, the C-reactive protein was assayed. The clinical outpatient follow-up was performed up to 180 days postoperatively.

Results: Although there were two postoperative infections, there was no graft contamination or difference between the groups in relation to the graft preparation time and to the 24-hour postoperative C-reactive protein assessment. The classic technique presented a longer graft harvesting time $(p=0.038)$, and there was no statistical difference between the 2 groups regarding the degree of contamination and consequent clinical infection, although 2 patients in group 2 presented with infection, with negative perioperative cultures.

Conclusion: Based on the results obtained, there was no association between graft contamination and the time or technique of its preparation. In addition, there was also no association between intraoperative contamination and the development of clinical infection, nor was there any sign of an association between the early alteration of Creactive protein and the onset of infection.
\end{abstract}

Conclusão: Com base nos resultados obtidos, não houve associação entre contaminação do enxerto com o tempo ou a técnica de sua preparação, tampouco entre a contaminação intraoperatória e o desenvolvimento de infecção clínica ou entre alteração precoce da proteína $C$ reativa e o surgimento de infecção.

\section{Introdução}

A reconstrução artroscópica do ligamento cruzado anterior (LCA) é procedimento eficaz para restaurar a estabilidade do joelho após sua lesão. ${ }^{1,2}$ Infecção após a reconstrução do LCA é complicação rara, mas potencialmente grave, com incidência entre $0,14 \%$ e $1,8 \%{ }^{1,3-7}$ o desenvolvimento do quadro infeccioso está associado a morbidade substancial (perda do enxerto usado na reconstrução, degeneração condral, artrofibrose e osteoartrose), além de perda funcional. ${ }^{8,9}$ No caso de infecção após reconstrução do LCA, sinais e sintomas como dor, derrame articular, aumento da temperatura e restrição do movimento são inespecíficos e podem surgir como alterações agudas ou tardias. ${ }^{7}$ Tais alterações têm baixa especificidade, pois podem estar presentes no pósoperatório normal, sendo isoladamente pouco úteis para confirmar infecção. Dessa forma, avaliação laboratorial complementar é importante para o diagnóstico. ${ }^{1,5,6,10}$

Entre as várias técnicas de reconstrução, os autoenxertos osso-tendão patelar-osso e o enxerto de tendões isquiotibiais são os mais usados para reconstrução primária do LCA e apresentam taxas de infecção semelhantes. ${ }^{11}$ Ambos reque- rem preparação em mesa auxiliar antes da fixação final. Os tendões flexores têm sido muito usados atualmente por apresentar menor dor residual, menor alteração de sensibilidade na região anterior do joelho, maior tolerância a atividades extenuantes e menor taxa de desenvolvimento de osteoartrite radiográfica. ${ }^{12-15}$ Existem duas técnicas para sua preparação: uma clássica, com a retirada total dos tendões flexores, e a outra que mantém sua inserção tibial. Diversos autores defendem que preservar essa inserção torna a cirurgia mais biológica, promove melhor propriocepção, melhor suprimento sanguíneo e serve como reforço à porção tibial do enxerto, que é considerada a parte mais frágil. ${ }^{16-20}$

Diante do exposto, o objetivo do presente estudo foi avaliar a taxa de contaminação de autoenxertos preparados a partir dos tendões flexores com as duas técnicas citadas e verificar se a contaminação intraoperatória está associada com o desenvolvimento de infecção clínica em pacientes submetidos à reconstrução do LCA. O objetivo secundário foi avaliar se a técnica de preparo do enxerto e o aumento do tempo de preparo - entre a retirada e o implante definitivo do mesmo - podem aumentar o risco de contaminação. 


\section{Material e Métodos}

Entre julho de 2016 e janeiro de 2017 foram coletados dados prospectivos de 124 pacientes submetidos à reconstrução primária do LCA feita em nossa instituição. Todos os pacientes que tiveram a reconstrução do LCA feita com os tendões flexores como enxerto foram incluídos. Os critérios de exclusão foram procedimentos cirúrgicos prévios no joelho a ser operado, uso do tendão dos flexores contralateral, outra fonte de enxerto e a não autorização quanto à participação no estudo. Este estudo foi apresentado ao e aprovado pelo Comitê de Ética e recebeu liberação CAAE no 48411115.0.0000.5127. Todos os participantes concordaram e assinaram o consentimento informado antes do início do estudo. Não foi oferecido qualquer incentivo financeiro para os pacientes participarem da pesquisa.

\section{Aspectos cirúrgicos da reconstrução do ligamento cruzado anterior}

No momento da indução anestésica o paciente foi preparado com tricotomia e feita dose profilática de cefazolina $2 \mathrm{~g}$ ou clindamicina $600 \mathrm{mg}$, em caso de alergia. O antibiótico foi mantido por 24 horas com administrações a cada oito horas. A antissepsia da pele foi feita com escovação macia com sabão de clorexidina, seguida da aplicação da solução alcoólica, sempre pelo mesmo pesquisador assistente. Após a colocação dos campos, acionava-se o torniquete e começava-se a marcar o tempo de cirurgia. Foi registrado o tempo do início do procedimento até a retirada do enxerto, do início até a fixação dele, total de cirurgia e de preparo do enxerto. $O$ tempo de preparo incluía o manuseio dos tendões e o tempo de espera até sua colocação, enquanto o tempo final da cirurgia era até finalizar a sutura da pele e desligar o torniquete.
Três cirurgiões sêniores fizeram todas as reconstruções. Foram duas técnicas usadas para retirada e preparo dos enxertos durante a reconstrução do LCA: técnica tradicional com colheita dos enxertos flexores, liberação da inserção tibial e preparação livre em mesa assistente (grupo 1); e a técnica biológica, com manutenção dessa inserção tibial (grupo 2). A técnica 1 foi executada pelo cirurgião Lúcio Honório de Carvalho Júnior e a técnica 2 executada pelos cirurgiões Eduardo Frois Temponi e Luiz Fernando Machado Soares.

\section{Grupo 1-Técnica clássica}

O enxerto foi retirado no início do procedimento através de uma incisão longitudinal de $2-3 \mathrm{~cm}$ ao longo a inserção distal da pata de ganso na tíbia proximal. Um fio de Vicril 2-0 era passado na parte mais distal de cada tendão - grácil e semitendíneo -, os quais eram desinseridos da tíbia com uso do bisturi e destacados do ventre muscular com extrator de tendões fechado. Os dois enxertos eram levados à mesa por um assistente que retirava a parte muscular, fazia o ajuste das bordas seguido do preparo e da mensuração dos tendões. Simultaneamente, o cirurgião sênior prosseguia com a artroscopia padrão, o inventário articular, tratamento das lesões associadas e preparo dos túneis (-Fig. 1A).

\section{Grupo 2-Técnica com preservação da inserção tibial}

No grupo 2, foi feito o mesmo acesso para a exposição dos tendões da pata de ganso. Após sua individualização, os tendões do semitendíneo e do grácil foram retirados com um extrator de tendões aberto. Na sequência, o enxerto começava a ser preparado, mantendo-se sua inserção tibial de modo a se obter um enxerto quádruplo, o qual ficava mantido entre a fáscia e o

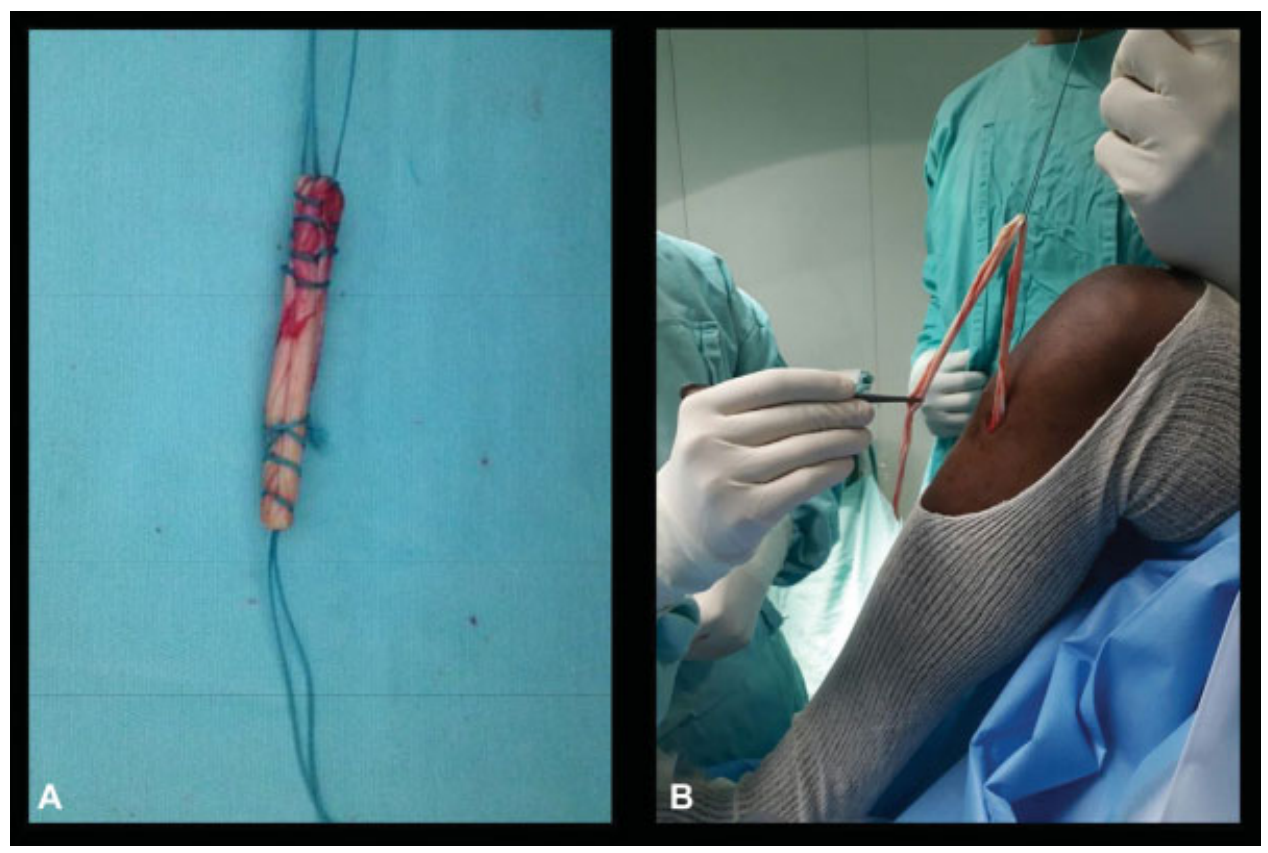

Fig. 1 Preparo dos enxertos flexores. A, grupo 1-técnica clássica com enxerto flexor livre; B, grupo 2-técnica com enxerto flexor inserido. 
subcutâneo enquanto, toda a parte artroscópica e de fixação se dava na mesma rotina do Grupo 1 (-Fig. 1B).

\section{Análise laboratorial}

Dois fragmentos com tamanho médio de $4 \times 4 \times 2 \mathrm{~mm}$ foram obtidos das sobras de uma das extremidades do enxerto de modo a não perturbar a integridade dele. 0 primeiro fragmento era obtido imediatamente após preparo do enxerto e o segundo imediatamente antes da sua passagem para fixação final, o tempo foi anotado. As duas amostras eram imediatamente colocadas em recipiente estéril com $2 \mathrm{ml}$ de solução fisiológica 0,9\% e enviadas para laboratório ao final da cirurgia, no qual cada uma era agitada por 1 min no vórtex, seu conteúdo líquido totalmente aspirado com agulha grossa e transferido para um frasco de hemocultura BacT/Alert FA® (bioMérieux AS, Lyon, França) como meio BHI. Esse meio de hemocultura era colocado na estufa BacT/Alert 3D® (bio-Mérieux AS, Lyon, França) na qual ficava por até 72 horas submetido a análises automatizadas a cada $10 \mathrm{~min}$. Se o sistema alertasse crescimento positivo, uma amostra desse material seria semeada para avaliação qualitativa na placa de Petri.

Ao frasco de cultura inicial era adicionado o conteúdo de um outro tubo de BHI e novamente misturado com o fragmento do enxerto no vórtex. Em seguida era feita a primeira semeadura na placa tripla (ágar sangue, ágar McConkey e ágar Manitol). A placa e o frasco do enxerto com BHI eram mantidos em incubação a 35,0 $\pm 2,0$ ○C por 72 horas em atmosfera ambiente. Com 24 e 48 horas eram feitas análises visuais e a amostra era semeada em nova placa. Após 72 h sem crescimento na placa e na máquina, o resultado era considerado negativo.

\section{Coleta de dados e pós-operatório}

Foram coletados dados antropométricos, idade, lateralidade, sexo, comorbidades, presença de lesões articulares associadas e o PCR de 24 horas. Nenhum paciente usou dreno no pós-operatório e o primeiro curativo era mantido fechado por 48 horas. Todos receberem alta hospitalar com 24 horas e foram reavaliados em consultas ambulatoriais programadas com sete, 14, 45, 90 e 180 dias. O diagnóstico de artrite séptica foi considerado com base na apresentação clínica associada à investigação laboratorial com hemograma, PCR, VHS e análise do liquido sinovial.

\section{Análise estatística}

Foi feito cálculo amostral prévio ao estudo e definido o número mínimo de 56 joelhos como necessário para tratamento estatístico (28 em cada grupo), considerando-se nível de significância de $5 \%$ e poder de teste de $80 \%$. Os dados foram apresentados através do valor das médias e dos desviospadrão. Os dados categóricos foram comparados com o teste do qui-quadrado e o teste exato de Fischer. Após verificar a normalidade das variáveis contínuas com o teste de Kolmogorov-Smirnov, calcularam-se a média das variáveis normais e a mediana das não normais. Em seguida, verificou-se se houve diferença significativamente estatística entre os grupos com o teste paramétrico t de Student para as variáveis normais e o teste não paramétrico de Mann-Whitney nas não normais. Significância foi estabelecida como o valor de 0,05. A análise estatística foi feita com SPSS, $20 ®$ (IBM Corp. Lançado 2011. IBM SPSS Statistics for Windows, versão 20.0 Armonk, NY: BM Corp).

\section{Resultados}

Foram avaliados 110 pacientes, havendo perda de seguimento de 14 pacientes (12,7\%). Os dados antropométricos e relacionados ao ato cirúrgico estão listados na - Tabela 1. Cinquenta e seis $(50,9 \%)$ pacientes não apresentaram lesões associadas, enquanto $26(23,6 \%)$ apresentaram lesão isolada do menisco medial, 18 (16,4\%) lesão do menisco lateral, seis $(11,0 \%)$ lesão em ambos os meniscos e quatro (3,6\%) outros padrões de lesão. As comorbidades presentes foram hipertensão, diabetes, hipotireoidismo, depressão, asma e tabagismo, sem diferença entre

Tabela 1 Avaliação das variáveis categóricas entre os grupos

\begin{tabular}{|c|c|c|c|c|c|c|}
\hline Variável & Categoria & Grupo 1 & Grupo 2 & Total & Valor $\mathrm{p}$ & Teste \\
\hline \multirow[t]{3}{*}{ Gênero } & Masculino & 30 & 64 & 94 & 0,756 & Qui-quadrado \\
\hline & Feminino & 6 & 10 & 16 & & \\
\hline & Total & 36 & 74 & 110 & & \\
\hline \multirow[t]{3}{*}{ Lado da lesão } & Esquerdo & 22 & 38 & 60 & 0,572 & Fisher \\
\hline & Direito & 14 & 36 & 50 & & \\
\hline & Total & 36 & 74 & 110 & & \\
\hline \multirow[t]{3}{*}{ Lesão associada } & Sem lesão & 20 & 36 & 56 & 0,446 & Qui-quadrado \\
\hline & Com lesão & 16 & 38 & 54 & & \\
\hline & Total & 36 & 74 & 110 & & \\
\hline \multirow[t]{3}{*}{ Artrite séptica (infecção clínica) } & Negativa & 34 & 70 & 104 & 0,488 & Qui-quadrado \\
\hline & Positiva & 0 & 2 & 2 & & \\
\hline & Total & 34 & 72 & 106 & & \\
\hline
\end{tabular}

Grupo 1, enxerto flexor livre; Técnica 2, enxerto flexor fixo. 
Tabela 2 Distribuição das comorbidades

\begin{tabular}{|l|l|l|l|l|l|l|}
\hline & Comorbidade & Grupo 1 & Grupo 2 & Total & Valor $\mathbf{p}$ & Teste \\
\hline \multirow{3}{*}{ Sem comorbidades } & Sim & 24 & 46 & 24 & ns & Qui-quadrado \\
\cline { 2 - 7 } & Não & 12 & 28 & 12 & & \\
\hline \multirow{3}{*}{ Tabagismo } & Sim & 4 & 12 & 4 & ns & Qui-quadrado \\
\cline { 2 - 7 } & Não & 32 & 62 & 32 & & \\
\hline \multirow{3}{*}{ Asma } & Sim & 2 & 8 & 2 & ns & Qui-quadrado \\
\cline { 2 - 7 } & Não & 34 & 66 & 34 & & \\
\hline \multirow{3}{*}{ Diabetes } & Sim & 0 & 2 & 0 & ns & Qui-quadrado \\
\cline { 2 - 7 } & Não & 36 & 72 & 36 & & \\
\hline \multirow{2}{*}{ Hipotireoidismo } & Sim & 2 & 2 & 2 & ns & Qui-quadrado \\
\cline { 2 - 7 } & Não & 34 & 72 & 34 & & \\
\hline \multirow{2}{*}{ Depressão } & Nim & 0 & 2 & 0 & ns & Qui-quadrado \\
\cline { 2 - 7 } & Não & 36 & 72 & 36 & & \\
\cline { 2 - 7 } & Não & 32 & 72 & 32 & & Qui-quadrado \\
\hline
\end{tabular}

os grupos (- Tabela 2). A única diferença significativa encontrada entre os dois grupos foi o tempo de retirada do enxerto. Todas as culturas foram negativas e o PCR entre os grupos também não apresentou diferença ( - Tabela 3).

Dois pacientes do grupo 2 apresentaram artrite séptica no pós-operatório $(1,8 \%)$, em fase aguda. 0 primeiro foi submetido a antibioticoterapia e a mais duas artroscopias para desbridamento. Observou-se o bom estado do enxerto em ambos os procedimentos, que permitiu a manutenção dele. Esse paciente era portador de diabetes tipo 1 de difícil controle, seu PCR de 24 horas foi de $39 \mathrm{mg} / \mathrm{dL}$ e suas culturas do enxerto foram negativas. O segundo caso era de um paciente hígido, também com as culturas negativas e que teve seu enxerto preservado durante a artroscopia de desbridamento. Ambos tiveram cultura no primeiro debridamento com crescimento de Staphylococcus epidermidis.

\section{Discussão}

O achado mais importante do presente estudo foi que não houve diferença estatística entre os dois grupos no que tange ao grau de contaminação e consequente infecção clínica, embora dois pacientes do grupo 2 tenham tido infecção com culturas perioperatórias negativas. Outro achado foi que o

Tabela 3 Análise estatística entre as variáveis comparando os dois grupos

\begin{tabular}{|c|c|c|c|c|}
\hline Variável & Técnica usada & Média & Desvio-padrão & Valor $\mathrm{p}$ \\
\hline \multirow[t]{2}{*}{ Tempo de retirada do enxerto (min) } & Grupo 1-técnica clássica & 10,1 & 2,7 & $\mathrm{p}<0,05$ \\
\hline & Grupo 2-técnica que mantém a inserção & 8,3 & 2,8 & \\
\hline \multirow[t]{2}{*}{ PCR 24h (mg/dL) } & Grupo 1-técnica clássica & 8,6 & 5,0 & ns \\
\hline & Grupo 2-técnica que mantém a inserção & 13,5 & 11,0 & \\
\hline Variável & Técnica usada & Mediana & Desvio-padrão & Valor $\mathrm{p}$ \\
\hline \multirow[t]{2}{*}{ Idade (anos) } & Grupo 1-técnica clássica & 30,50 & 8,8 & ns \\
\hline & Grupo 2-técnica que mantém a inserção & 30,00 & 8,3 & \\
\hline \multirow[t]{2}{*}{ Peso $(\mathrm{kg})$} & Grupo 1-técnica clássica & 84,00 & 10,6 & \multirow[t]{2}{*}{ ns } \\
\hline & Grupo 2-técnica que mantém a inserção & 78,00 & 14,9 & \\
\hline \multirow[t]{2}{*}{ Altura $(\mathrm{cm})$} & Grupo 1-técnica clássica & 173,00 & 10,6 & \multirow[t]{2}{*}{ ns } \\
\hline & Grupo 2-técnica que mantém a inserção & 176,00 & 6,9 & \\
\hline \multirow[t]{2}{*}{ Tempo de preparo do enxerto (min) } & Grupo 1-técnica clássica & 24,50 & 6,0 & \multirow[t]{2}{*}{ ns } \\
\hline & Grupo 2-técnica que mantém a inserção & 27,00 & 7,0 & \\
\hline \multirow[t]{2}{*}{ Tempo total de cirurgia (min) } & Grupo 1-técnica clássica & 52,00 & 8,7 & \multirow[t]{2}{*}{ ns } \\
\hline & Grupo 2-técnica que mantém a inserção & 52,00 & 7,9 & \\
\hline
\end{tabular}


tempo de preparo e fixação do enxerto em nada interferiu com as taxas de contaminações dos enxertos. Dois casos de infecção foram descritos no grupo 2 (1,8\%), ambos diagnosticados em fase aguda e tratados em tempo hábil para se evitarem danos maiores aos enxertos. Um dos casos era de um paciente com diabetes tipo 1 que apresentou problemas no controle glicêmico no pós-operatório imediato, fator que pode contribuir para o surgimento de infecções, tanto que alguns estudos colocam a presença de diabetes como critério de exclusão. ${ }^{11,21,22}$ Não podemos comprovar se a fonte foi o enxerto, uma vez que todas as suas cultuas foram negativas. A taxa de contaminação nas culturas dos enxertos no presente estudo foi de $0 \%$, sendo diferente do que observado em estudos similares ( Tabela 4). ${ }^{11,21,23-25}$ Existe grande variação nos métodos de antissepsia, cultura e incubação descritos. Alguns usaram degermante à base de iodo, ${ }^{21,25}$ outros não citaram o degermante, ${ }^{11,22,23} \mathrm{em}$ alguns foi feita cultura para anaeróbios ${ }^{11,23}$ e em um dos trabalhos o tempo de incubação foi de até 14 dias. $^{24}$ Sabe-se, por exemplo, que fatores como o uso do clorexidine pode influenciar o número de culturas positivas, uma vez que esse degermante comprovadamente reduz os índices de infecções pós-operatória e a colonização da pele. ${ }^{26-28}$

A análise microbiológica do enxerto em condições reais de uso nos estudos, sem intervenção contaminante ou descontaminante, mostra culturas positivas que variam de $2 \%$ a $23 \%$ quando do uso dos tendões flexores. ${ }^{11,21,23-25,29}$ Entre esses estudos, apenas no de Nakayama et al. ${ }^{21}$ houve um caso de cultura positiva no enxerto e artrite séptica pósoperatória no mesmo paciente. Contudo, o germe contaminante, Staphylococcus aureus meticilina sensível (MSSA), era diferente do isolado na infecção, Staphylococcus aureus meticilina resistente (MRSA) (-Tabela 4). Essa falta de correlação entre a clínica infecciosa e a microbiologia perioperatória pode sugerir que a contaminação do enxerto confeccionado sem intercorrências tenha pequeno papel na causa de infecções no contexto atual da cirurgia de reconstrução do LCA.

Tabela 4 Avaliação da contaminação e infecção em pacientes submetidos à reconstrução do ligamento cruzado anterior do joelho revisão da literatura

\begin{tabular}{|c|c|c|c|c|}
\hline Autor & $\mathrm{N}$ total & Culturas positivas / (\%) & Germe (n) & Infecções clínicas / (\%) \\
\hline \multirow[t]{3}{*}{ Hantes et al., $2008^{11}$} & \multirow[t]{3}{*}{30} & \multirow[t]{3}{*}{$4 /(13 \%)$} & Staphylococcus aureus (2) & \multirow[t]{3}{*}{0} \\
\hline & & & Acinetobacter (1) & \\
\hline & & & Staphylococcus epidermidis (1) & \\
\hline \multirow[t]{7}{*}{ Gavriilidis et al., $2009^{23}$} & \multirow[t]{7}{*}{89} & \multirow[t]{7}{*}{$9 /(10 \%)$} & S. epidermidis (2) & \multirow[t]{7}{*}{0} \\
\hline & & & Enterococcus (2) & \\
\hline & & & Staphylococcus capitis (1) & \\
\hline & & & Peptostreptococcus (1) & \\
\hline & & & Corynebacterium (1) & \\
\hline & & & Bacillus cereus (1) & \\
\hline & & & Propionibacterium granulosum (1) & \\
\hline \multirow[t]{7}{*}{ Plante et al., $2013^{24}$} & \multirow[t]{7}{*}{30} & \multirow[t]{7}{*}{$7 /(23 \%)$} & S. aureus (1) & \multirow[t]{7}{*}{0} \\
\hline & & & Streptococcus viridians (1) & \\
\hline & & & Corynebacterium (1) & \\
\hline & & & Staphylococcus no aureus (1) & \\
\hline & & & Lactobacillus (1) & \\
\hline & & & Propionibacterium acnes (1) & \\
\hline & & & Escherichia coli (1) & \\
\hline Nakayama et al., $2012^{21}$ & 50 & $1 /(2 \%)$ & Bacillus sp. (1) & $1 /(2 \%)$ \\
\hline \multirow[t]{3}{*}{ Barbier et al., $2015^{25}$} & \multirow[t]{3}{*}{25} & \multirow[t]{3}{*}{$3 /(12 \%)$} & Staphylococcus hominis (1) & \multirow[t]{3}{*}{0} \\
\hline & & & Staphylococcus capitis (1) & \\
\hline & & & Candida parapsilosis (1) & \\
\hline \multirow[t]{5}{*}{ Bradan et al., $2016^{22}$} & \multirow[t]{5}{*}{60} & \multirow[t]{5}{*}{$10 /(16,7 \%)$} & Staphylococcus epidermidis (4) & \multirow[t]{5}{*}{0} \\
\hline & & & Staphylococcus aureus (2) & \\
\hline & & & Acinetobacter (2) & \\
\hline & & & Bacillus spp. (1) & \\
\hline & & & Citrobacter spp. (1) & \\
\hline (este estudo) & 110 & $0 /(0 \%)$ & No growth & $2 /(1,8 \%)$ \\
\hline
\end{tabular}


Quanto à avaliação complementar, Hantes et al. ${ }^{11}$ não encontraram diferenças entre o PCR de enxertos contaminados ou não com 24 horas de pós-operatório. Situação semelhante foi observada por Gavriilidis et al., ${ }^{23}$ que encontraram PCR elevado no 4 o dia e valor normal no 20。 dia, mas ambos sem diferença entre os grupos com enxerto contaminado ou não e por Bradan et al., ${ }^{22}$ os quais não obtiveram diferenças de PCR entre os grupos de enxerto com ou sem contaminação nos dias sete, 12 e 20 de pós-operatório. Esses estudos, no entanto, não apresentaram casos de infecção clínica, quando pode ser encontrado um aumento significativo do $\mathrm{PCR}^{1,5,6,10}$ Da mesma forma nenhuma variação significativa foi observada entre os valores de PCR de $24 \mathrm{~h}$ no presente estudo.

Quando avaliada a variável tempo, Hantes et al. ${ }^{11}$ obtiveram tempo médio de preparo do enxerto flexor de 19 (1621) min e entre coleta e o implante do enxerto de 38 (2843) min. Esse autor comparou com o tempo de preparo e de implante do enxerto osso-tendão patelar-osso e encontrou tempo significativamente menor de preparo do patelar, mas sem diferença na comparação do tempo de implante. Com isso, não concluiu sua hipótese de que o tempo maior de preparo seria responsável por uma maior incidência de contaminação no enxerto de tendão dos flexores. Gavriilidis et al. $^{23}$ apresentaram tempo médio de preparo de 16 $( \pm 2)$ min e o tempo médio entre coleta e implante do enxerto de flexores foi de $20( \pm 2)$ min. Este estudo também não teve amostra suficiente para confirmar a hipótese do tempo e maior chance de contaminação, mas o autor afirma existir grande correlação dessa associação. Judd et al. ${ }^{30}$ também afirmam que não há dúvida de que o intervalo de tempo entre a colheita do tendão flexor e implantação no joelho seria um importante critério para a possibilidade de contaminação. No entanto, seu estudo não apresenta números que comprovem tal hipótese. 0 presente estudo comparou duas técnicas de retirada e preparo dos tendões flexores e houve relação significativa apenas entre a variável tempo de retirada do enxerto e a técnica usada ( $\mathrm{p}=0,038$ ), indicando que os indivíduos em que a técnica usada foi a técnica clássica grupo 1-(10,1 $\mathrm{min}$ ) apresentaram maior tempo médio de retirada do enxerto do que os que fizeram a técnica de preservação da inserção - grupo $2-(8,3 \mathrm{~min})$. Tal fato, no entanto, não apresentou relação com maior exposição do enxerto ou maior chance de contaminação. ${ }^{23,30}$ Não houve diferença entre as duas técnicas quanto aos valores obtidos de tempo entre o início da cirurgia até a fixação do enxerto, na duração total de cirurgia e no tempo gasto para preparo do enxerto. Com isso, a influência da variável tempo não pode ser considerada diferente na possibilidade de ocorrência de contaminação e/ou infecção.

Diversas limitações podem ser descritas no presente estudo. O protocolo microbiológico adotado foi usado para amostras sem indícios ou suspeitas de conter germes anaeróbicos, fez com que certos germes tipicamente encontrados na pele não pudessem ser identificados, como previamente reportado. ${ }^{23}$ As amostras colhidas e colocadas no soro ficaram na sala cirúrgica até o fim do procedimento (em torno de 30 a 40 minutos), podendo ser um fator de redução da sensibilidade do exame. O presente estudo foi conduzido como atividade clínica, com a aplicação real dos procedimentos na rotina do hospital, o que inviabilizou longas incubações ou uso de meio de cultura e atmosfera para anaeróbios. Outros trabalhos que avaliaram culturas de amostras "estéreis do enxerto mantiveram incubação de cinco até 14 dias, enquanto deixamos por apenas três dias, o que reduziu a chance de identificação de germes fastidiosos. Outra limitação foi o não seguimento laboratorial do paciente durante o pós-operatório, o que aumentaria o custo e implicaria modificação da rotina clínica. Apesar da taxa de contaminação de $0 \%$ encontrada no presente estudo, nossos achados reafirmam passos importantes da prevenção de infecções operatórias como a degermação da pele, antibioticoprofilaxia, execução da cirurgia por parte do cirurgião sênior, proteção meticulosa do enxerto, especialmente quando há atraso na sua implantação. Através do melhor conhecimento dos fatores relacionados à contaminação dos enxertos, medidas de prevenção de quadro infecciosos poderão ser tomadas. Além disso, estudos posteriores poderão confirmar a real contribuição de fatores como agressão cirúrgica, dispositivo de fixação do enxerto, número de auxiliares, uso de dreno, cuidados com a ferida operatória, doenças associadas, grau de atividade esportiva pré-operatória.

\section{Conclusão}

Com base nos resultados obtidos, não houve associação entre contaminação do enxerto com o tempo ou a técnica de sua preparação, tampouco entre a contaminação intraoperatória e o desenvolvimento de infecção clínica.

\section{Conflitos de interesse}

O autor Lúcio Honório de Carvalho Júnior declara ter recebido apoio à pesquisa do laboratório farmacêutico Aché para arcar com custos da análise estatística do trabalho. Os outros autores declaram não haver conflitos de interesse.

\section{Referências}

1 Schuster P, Schulz M, Immendoerfer M, Mayer P, Schlumberger M, Richter J. Septic arthritis after arthroscopic anterior cruciate ligament reconstruction: evaluation of an arthroscopic graftretaining treatment protocol. Am J Sports Med 2015;43(12): 3005-12

2 Leathers MP, Merz A, Wong J, Scott T, Wang JC, Hame SL. Trends and demographics in anterior cruciate ligament reconstruction in the United States. J Knee Surg 2015;28(05):390-4

3 Benner RW, Shelbourne KD, Freeman H. Infections and patellar tendon ruptures after anterior cruciate ligament reconstruction: a comparison of ipsilateral and contralateral patellar tendon autografts. Am J Sports Med 2011;39(03):519-25

4 Katz LM, Battaglia TC, Patino P, Reichmann W, Hunter DJ, Richmond JC. A retrospective comparison of the incidence of bacterial infection following anterior cruciate ligament reconstruction with autograft versus allograft. Arthroscopy 2008;24(12):1330-5

5 Torres-Claramunt R, Pelfort X, Erquicia J, Gil-González S, Gelber PE, Puig L, et al. Knee joint infection after ACL reconstruction: 
prevalence, management and functional outcomes. Knee Surg Sports Traumatol Arthrosc 2013;21(12):2844-49

6 Wang C, Ao Y, Wang J, Hu Y, Cui G, Yu J. Septic arthritis after arthroscopic anterior cruciate ligament reconstruction: a retrospective analysis of incidence, presentation, treatment, and cause. Arthroscopy 2009;25(03):243-9

7 Williams RJ III, Laurencin CT, Warren RF, Speciale AC, Brause BD, O'Brien S. Septic arthritis after arthroscopic anterior cruciate ligament reconstruction. Diagnosis and management. Am J Sports Med 1997;25(02):261-7

8 Frank M, Schmucker U, David S, Matthes G, Ekkernkamp A, Seifert J. Devastating femoral osteomyelitis after anterior cruciate ligament reconstruction. Knee Surg Sports Traumatol Arthrosc 2008; 16(01):71-4

9 Van Tongel A, Stuyck J, Bellemans J, Vandenneucker H. Septic arthritis after arthroscopic anterior cruciate ligament reconstruction: a retrospective analysis of incidence, management and outcome. Am J Sports Med 2007;35(07):1059-63

10 Mouzopoulos G, Fotopoulos VC, Tzurbakis M. Septic knee arthritis following ACL reconstruction: a systematic review. Knee Surg Sports Traumatol Arthrosc 2009;17(09):1033-42

11 Hantes ME, Basdekis GK, Varitimidis SE, Giotikas D, Petinaki E, Malizos KN. Autograft contamination during preparation for anterior cruciate ligament reconstruction. J Bone Joint Surg Am 2008;90(04):760-4

12 Christel P. Graft choice in ACL reconstruction: which one and why? In:Sanchis-Alfonso V, Monllau JC, eds. The ACL-deficient knee. A problem solving approach. London: Springer Verlag; 2013:105-12

13 Aglietti P, Giron F, Buzzi R, Biddau F, Sasso F. Anterior cruciate ligament reconstruction: bone-patellar tendon-bone compared with double semitendinosus and gracilis tendon grafts. A prospective, randomized clinical trial. J Bone Joint Surg Am 2004;86 (10):2143-55

14 Pandarinath R, Ciccotti M, DeLuca PF. Current trends in ACL reconstruction among professional team physicians. In: Proceedings of the AAOS 2011 Annual Meeting, 2011, paper 324

15 Pinczewski LA, Lyman J, Salmon LJ, Russell VJ, Roe J, Linklater J. A 10-year comparison of anterior cruciate ligament reconstructions with hamstring tendon and patellar tendon autograft: a controlled, prospective trial. Am J Sports Med 2007;35(04):564-74

16 Kim SJ, Kim HK, Lee YT. Arthroscopic anterior cruciate ligament reconstruction using autogenous hamstring tendon graft without detachment of the tibial insertion. Arthroscopy 1997;13(05): 656-60

17 Gupta R, Bahadur R, Malhotra A, Masih GD, Gupta P. Anterior Cruciate Ligament Reconstruction Using Hamstring Tendon Autograft With Preserved Insertions. Arthrosc Tech 2016;5(02): e269-e74

18 Deie M, Ochi M, Ikuta Y. High intrinsic healing potential of human anterior cruciate ligament. Organ culture experiments. Acta Orthop Scand 1995;66(01):28-32
19 Sonnery-Cottet B, Lavoie F, Ogassawara R, Scussiato RG, Kidder JF, Chambat P. Selective anteromedial bundle reconstruction in partial ACL tears: a series of 36 patients with mean 24 months follow-up. Knee Surg Sports Traumatol Arthrosc 2010;18(01): 47-51

20 Sonnery-Cottet B, Saithna A, Cavalier M, Kajetanek C, Temponi EF, Daggett $\mathrm{M}$, et al. Anterolateral Ligament Reconstruction Is Associated with Significantly Reduced ACL Graft Rupture Rates at a Minimum Follow-up of 2 Years: A Prospective Comparative Study of 502 Patients from the SANTI Study Group. Am J Sports Med 2017;45(07):1547-57

21 Nakayama H, Yagi M, Yoshiya S, Takesue Y. Micro-organism colonization and intraoperative contamination in patients undergoing arthroscopic anterior cruciate ligament reconstruction. Arthroscopy 2012;28(05):667-71

22 Badran MA, Moemen DM. Hamstring graft bacterial contamination during anterior cruciate ligament reconstruction: clinical and microbiological study. Int Orthop 2016;40(09):1899-903

23 Gavriilidis I, Pakos EE, Wipfler B, Benetos IS, Paessler HH. Intraoperative hamstring tendon graft contamination in anterior cruciate ligament reconstruction. Knee Surg Sports Traumatol Arthrosc 2009;17(09):1043-7

24 Plante MJ, Li X, Scully G, Brown MA, Busconi BD, DeAngelis NA. Evaluation of sterilization methods following contamination of hamstring autograft during anterior cruciate ligament reconstruction. Knee Surg Sports Traumatol Arthrosc 2013;21(03): 696-701

25 Barbier O, Danis J, Versier G, Ollat D. When the tendon autograft is dropped accidently on the floor: A study about bacterial contamination and antiseptic efficacy. Knee 2015;22(05):380-3

26 Paocharoen V, Mingmalairak C, Apisarnthanarak A. Comparison of surgical wound infection after preoperative skin preparation with $4 \%$ chlorhexidine [correction of chlohexidine] and povidone iodine: a prospective randomized trial. J Med Assoc Thai 2009;92 (07):898-902

27 Lee I, Agarwal RK, Lee BY, Fishman NO, Umscheid CA. Systematic review and cost analysis comparing use of chlorhexidine with use of iodine for preoperative skin antisepsis to prevent surgical site infection. Infect Control Hosp Epidemiol 2010;31(12): 1219-29

28 Noorani A, Rabey N, Walsh SR, Davies RJ. Systematic review and meta-analysis of preoperative antisepsis with chlorhexidine versus povidone-iodine in clean-contaminated surgery. Br J Surg 2010;97(11):1614-20

29 Izquierdo R Jr, Cadet ER, Bauer R, Stanwood W, Levine WN, Ahmad CS. A survey of sports medicine specialists investigating the preferred management of contaminated anterior cruciate ligament grafts. Arthroscopy 2005;21(11):1348-53

30 Judd D, Bottoni C, Kim D, Burke M, Hooker S. Infections following arthroscopic anterior cruciate ligament reconstruction. Arthroscopy 2006;22(04):375-84 